
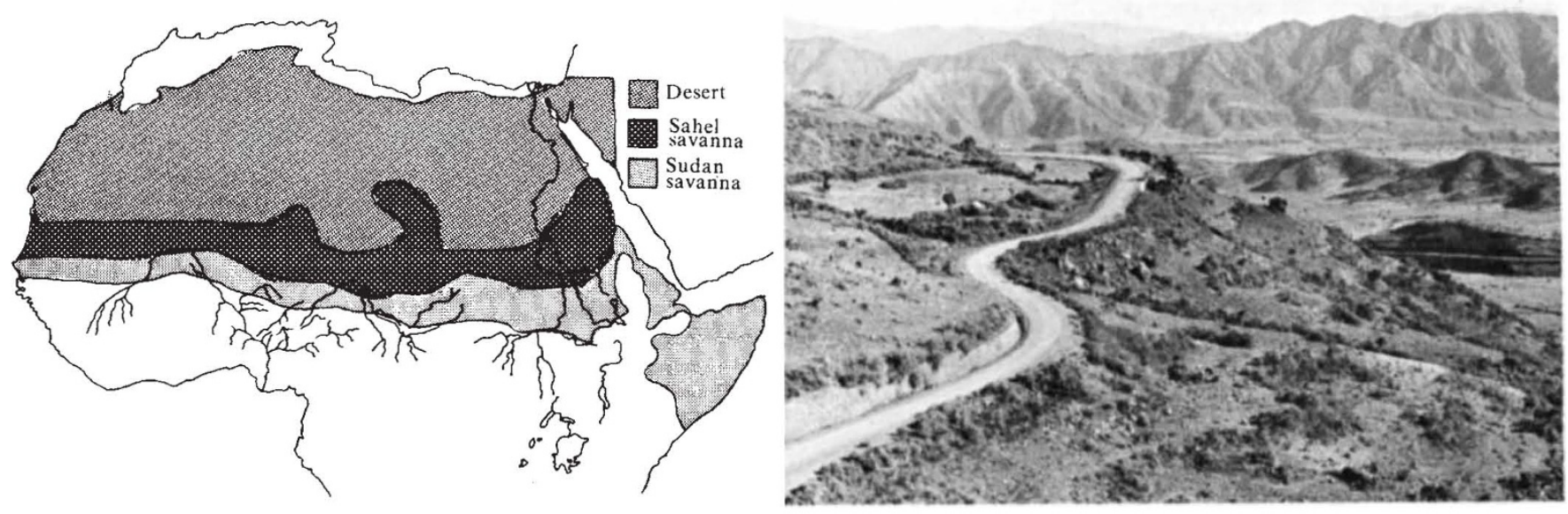

\title{
What next in the Sahel?
}

ThreE years after the great drought that brought the Sahel into the headlines opinion as to the future of the two million square kilometre region are still sharply divided. This was apparent at a recent meeting held in London under the joint auspices of the Royal Geographical Society and the Royal Society of Arts, curiously entitled 'Sahel ecology: possible improvement'.

The meeting brought together a heterogeneous collection of speakersbotanists, geographers, zoologists, but apparently few ecologists-from several countries, although only one was from the region itself. After more than eight hours of papers and discussion, little new was suggested that could be expected to improve conditions in what, Professor A. 'T. Grove pointed out, is one of the poorest inhabited regions of the world.

He suggested that the Sahel might never again be as productive as it had become by the mid-1960s. By that time, 30 years of uncontrolled 'development', largely in the form of well-drilling and veterinary activities, had led to a livestock population of about 10 million cattle, 10 million sheep and uncounted goats. With a human population given as 10 million, but perhaps as much as 25 million, the carrying capacity of the region had been reached, if not exceeded.

Even so, the drought of the early 1970 s cost less in human suffering than the last such major event in 1913, although livestock losses were very much greater. (It is perhaps worth noting that the Food and Agriculture Organisation had been warned, by one of its own staff members, of the possibility of some such disaster as a result of its policy of encouraging increased livestock production in the Sahelian countries. The warnings did not suit the organisation's livestock experts however, and went unheeded).
Some speakers maintained that the drought was not so much due to a shortage of water as to lack of food for both livestock and humans. As people and their livestock were driven from the northern Sahel by lack of sustence, they caused grazing and other pressures on the more productive south resulting in rapid degradation and erosion of soils already exploited to the maximum. It is in the south that the most serious damage may have been done.

What is needed to rehabilitate the region is the business of the Sahel Research Institute at Bamako, Mali, whose director, Dr Ousmane Silla from Senegal, was the region's sole contributor to the meeting. The institute, now getting under way with help from various United Nations and other agencies, is seen as the coordinating centre for research in the individual Sahelian countries, where funds and expertise are too scarce to be wasted on ill-conceived projects or duplication of effort.

The institute is to give priority to 'harmonisation' of research and to training indigenous young scientists in the disciplines applicable to research in the region, where most experience and knowledge at present comes from foreign experts. An early start is planned on projects which include studies of the water balance in the region; the crops most suitable for the various parts of the region; improvement and 'commercialisation' of livestock; and the human, ethnic, and social problems of the region as a whole, including those of health and nutrition. The development of freshwater fisheries was also mentioned-a field in which FAO is interested in the Sahel--but Dr Silla had no comment to offer on the suggestion that what the Sahel's agriculture needed for more effective cropping was mineral nutrients rather than water.
Apart from Dr Silla's presentation, appreciation of the need to consider the human population was more apparent in the discussions than in the papers themselves. Papers from three visitors from the Office of Land Studies of the University of Arizona suggested that the Sahel's problems could be at least partly solved by the introduction of large-scale industrial crops such as the oil-bearing jojoba (Simundsia sinensis) and rubber-producing guayule (parthenium argentatum). Among those disagreeing with this approach was Professor Cloudsley Thompson, who pointed out that all such big schemes in this type of region had failed, even that in the Gezira being by no means as successful as had been claimed. His suggestion would be for many small, diverse projects using local resources to fulfil local needs. The failure of any one would not be disastrous. Dry farming should be developed, particularly in view of the risks of parasitic diseases attendant upon large irrigation schemes, and of the availability of modern techniques for dune fixation and desalination.

No one expects a miracle in this difficult and remote region. Perhaps the biggest danger lies in its exploitation by outside interests. Climatologists at the meeting seemed to feel that the danger of another series of drought years was not imminent, but maximisation of production in normal times will always lay the Sahel open to disasters such as that which has inspired so much talk (and possibly, so little action) since 1975. Given disinterested advice and aid the peoples of the Sahel are perhaps better able to decide what is best for their own future than are the innumerable agencies, international, bi-lateral and charitable, at present offering assistance and not always very practical suggestions.

Peter Collins 